\title{
Monitoring the charge-transfer process in a Nd-doped semiconductor based on photoluminescence and SERS technology
}

Shuo Yang ${ }^{1}$, Jiacheng Yao ${ }^{2,3,4}$, Yingnan Quan ${ }^{2,3,4}$, Mingyue $\mathrm{Hu}^{2,3,4}$, Rui Su${ }^{2,3,4}$, Ming Gao $\mathbb{D}^{2,3,4}$, Donglai Han ${ }^{5}$ and Jinghai Yang $2,3,4$

\begin{abstract}
Surface-enhanced Raman scattering (SERS) and photoluminescence (PL) are important photoexcitation spectroscopy techniques; however, understanding how to analyze and modulate the relationship between SERS and PL is rather important for enhancing SERS, having a great effect on practical applications. In this work, a charge-transfer (CT) mechanism is proposed to investigate the change and relationships between SERS and PL. Analyzing the change in PL and SERS before and after the adsorption of the probe molecules on $\mathrm{Nd}$-doped $\mathrm{ZnO}$ indicates that the unique optical characteristics of $\mathrm{Nd}^{3+}$ ions increase the SERS signal. On the other hand, the observed SERS can be used to explain the cause of PL background reduction. This study demonstrates that modulating the interaction between the probe molecules and the substrate can not only enhance Raman scattering but also reduce the SERS background. Our work also provides a guideline for the investigation of $\mathrm{CT}$ as well as a new method for exploring fluorescence quenching.
\end{abstract}

\section{Introduction}

Surface-enhanced Raman scattering (SERS), as a powerful spectral technology, has been widely used in the fields of chemistry, pharmaceuticals, biosensors, food detection, and environmental monitoring owing to its high sensitivity and fast response ${ }^{1-3}$. In general, the enhanced magnitude of SERS is associated with two mechanisms. One is the electromagnetic mechanism, which is related to the localized surface plasmon resonance of the metal nanoparticles (NPs) ${ }^{4}$. The other is the chemical mechanism, which mainly originates from the charge transfer $(\mathrm{CT})$ between adsorbed molecules and SERS-active substrates ${ }^{5}$. On the other hand, the photoluminescence $(\mathrm{PL})$ of the substrates and adsorbed molecules, acting as a broad-continuum background of SERS

Correspondence: Ming Gao (gaomingphy@126.com), Donglai Han (DLhan_1015@163.com) or Jinghai Yang (jhyang1@jlnu.edu.cn) ${ }^{1}$ College of Science, Changchun University, Changchun 130022, China ${ }^{2}$ National Demonstration Centre for Experimental Physics Education, Jilin Normal University, Siping 136000, China

Full list of author information is available at the end of the article spectroscopy, has a great effect on SERS spectroscopy and evenly reduces the distinctiveness of the Raman $\operatorname{tag}^{6,7}$. Thus, controlling and utilizing PL, contributed by substrates and adsorbed molecules, to enhance the SERS signal is a key problem that urgently needs to be solved. Recently, Ren et al. successfully resolved these limitations by proposing a method for recovering native chemical information from SERS using plasmonic PL and quantitatively investigated the relationship between the PL and the SERS background ${ }^{8}$. However, the development of simpler and more effective methods to remove the negative effects of PL on SERS and to directly analyze the relationship between SERS and PL is of significance for both fundamental research and practical application.

In the PL generation mechanism, photoexcited electrons transition to a high energy level. Because of highenergy-level instability, these electrons usually transition to a low energy level and emit photons ${ }^{9,10}$. This inspires us to use electrons as a link to explore the relationship between PL and SERS in the CT mechanism and investigate how PL affects the SERS signal. SERS technology

\section{(c) The Author(s) 2020}

(c) (i) Open Access This article is licensed under a Creative Commons Attribution 4.0 International License, which permits use, sharing, adaptation, distribution and reproduction c. in any medium or format, as long as you give appropriate credit to the original author(s) and the source, provide a link to the Creative Commons license, and indicate if changes were made. The images or other third party material in this article are included in the article's Creative Commons license, unless indicated otherwise in a credit line to the material. If material is not included in the article's Creative Commons license and your intended use is not permitted by statutory regulation or exceeds the permitted use, you will need to obtain permission directly from the copyright holder. To view a copy of this license, visit http://creativecommons.org/licenses/by/4.0/. 

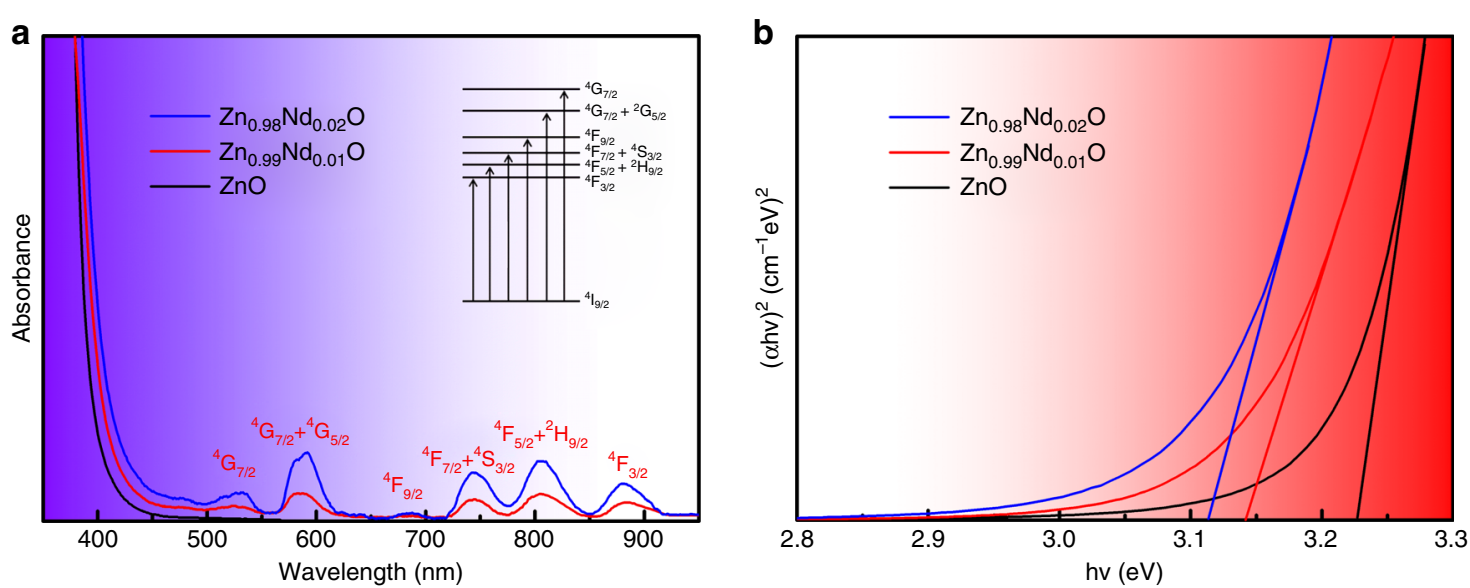

Fig. 1 The UV-vis absorption spectra and of Optical energy band gap $\mathbf{Z n O}$ and $\mathbf{Z n}_{\mathbf{1 - x}} \mathbf{N d}_{\mathbf{x}} \mathbf{O}$. a The UV-vis absorption spectra of $\mathrm{ZnO}$ and $\mathrm{Zn}_{1-x} \mathrm{Nd}_{x} \mathrm{O}(x=0.00,0.01,0.02)$. b Optical energy band gap of $\mathrm{ZnO}$ and $\mathrm{Zn}_{1-x} \mathrm{Nd}_{x} \mathrm{O}(x=0.00,0.01,0.02)$

has been widely used to monitor the charge transport of substrate-molecular junctions ${ }^{11,12}$. Generally, when a semiconductor is used as a SERS substrate, only the CT enhancement mechanism contributes to SERS signals. However, exploring the relationship between SERS and $\mathrm{PL}$ of pure semiconductors is not obvious and thus is not convenient to analyze. Previously, we introduced impurity ions to optimize the matrix semiconductor ${ }^{10,13}$. The intra$4 f$ emission spectra of $\mathrm{Nd}^{3+}$ are characterized by narrow lines with high color purity because the $4 f$ electrons of rare-earth ions are shielded from external forces by the outer $5 s$ and $5 p$ electrons ${ }^{14}$. Thus, incorporating $\mathrm{Nd}^{3+}$ ions into a semiconductor might be an effective way to enhance the SERS signal. On the other hand, the characteristic PL peaks of $\mathrm{Nd}^{3+}$ ions can be used to analyze the relationship between PL and SERS. In this study, the nanomaterial $\mathrm{ZnO}$ was selected as a SERS substrate owing to its good optical stability and relatively high SERS activity among the reported semiconductor nanomaterials ${ }^{15,16}$.

In this work, we successfully synthesized Nd-doped $\mathrm{ZnO}\left(\mathrm{Zn}_{1-x} \mathrm{Nd}_{x} \mathrm{O}\right)$ as a SERS substrate in which $\mathrm{Nd}$ doping was performed using a simple chemical method. Here, we creatively used the CT mechanism to establish the relationship between SERS and PL and examined the change in SERS and PL caused by the CT mechanism in detail. We found that both $\mathrm{Nd}^{3+}$ ions and probe molecule fluorescence quenching promote $\mathrm{CT}$, enhance the SERS effect, and reduce the SERS background. This is thus the first example of using PL to enhance SERS and provides a new method for exploring fluorescence quenching.

$\mathrm{Zn}_{1-x} \mathrm{Nd}_{x} \mathrm{O}(x=0.00,0.005,0.01,0.015,0.0175,0.02$, 0.0225 , and 0.03$)$ was prepared via the coprecipitation method (details regarding the synthesis are presented in the Supporting Information, Fig. S1). X-ray diffraction
(XRD) patterns (Fig. S2) revealed that the solubility limit of $\mathrm{Nd}^{3+}$ ions is $\sim 0.02$ in the $\mathrm{Zn}_{1-x} \mathrm{Nd}_{x} \mathrm{O}$ structure and that excessive doping causes the precipitation of $\mathrm{Nd}_{2} \mathrm{O}_{3}$ $\mathrm{NPs}^{17}$. The morphologies of $\mathrm{ZnO}$ and $\mathrm{Zn}_{0.98} \mathrm{Nd}_{0.02} \mathrm{O}$ were examined via scanning electron microscopy (SEM) and transmission electron microscopy (TEM). The SEM images show that pure $\mathrm{ZnO}$ is a NP, aggregating with a diameter of $\sim 100 \mathrm{~nm}$ (Fig. S3a); after $\mathrm{Nd}$ doping, $\mathrm{Zn}_{0.98} \mathrm{Nd}_{0.02} \mathrm{O}$ is a 3D urchin-like nanostructure with a diameter of $2 \mu \mathrm{m}$ (Fig. S3c). Figure S3b, d (e.g., TEM images) shows that the surface area increases after doping, which improves the adsorption capacity. Among these eight samples with different doping amounts, we selected 0,1 , and $2 \%$ representative data for subsequent research. The UV-vis absorption spectra of $\mathrm{Zn}_{1-x} \mathrm{Nd}_{x} \mathrm{O}(x=0.00$, $0.01,0.02)$ are shown in Fig. 1a. It is noteworthy that there are some characteristic peaks of $\mathrm{Nd}^{3+}$ ions at 879.4, 805.2, $742.5,685.1,578.2$, and $521.0 \mathrm{~nm}$ corresponding to intra$4 f$ shell electron transitions of $\mathrm{Nd}^{3+}$ ions ${ }^{18}$, as shown in the inset of Fig. 1a. It is well known that optical absorption properties are associated with the optical band gap (Eg), which can be obtained by Tauc's formula $(\alpha h v)^{2}=$ $h v-E g$, as shown in Fig. $1 b^{19}$. The band gaps of $\mathrm{Zn}_{1-x} \mathrm{Nd}_{x} \mathrm{O}(x=0.00,0.01,0.02)$ were derived to be 3.23 , 3.14 , and $3.11 \mathrm{eV}$, respectively. $\mathrm{Zn}_{1-x} \mathrm{Nd}_{x} \mathrm{O}$ has a smaller band gap value, indicating that it has a preferable optical absorption property, making the interband charge transition easier.

To explore the relationship between SERS and PL, we obtained SERS and PL spectra measured with laser lines of $514.5 \mathrm{~nm}$. 4-Mpy $\left(\mathrm{C}_{5} \mathrm{H}_{5} \mathrm{NS}\right)$ was selected as a probe, and the SERS spectra of 4-MPy adsorbed on $\mathrm{Zn}_{1-x} \mathrm{Nd}_{x} \mathrm{O}$ are shown in Fig. 2a (several representative concentrations are shown in Fig. 2a, and other concentrations are given in the Supporting Information, Fig. S4). The SERS 

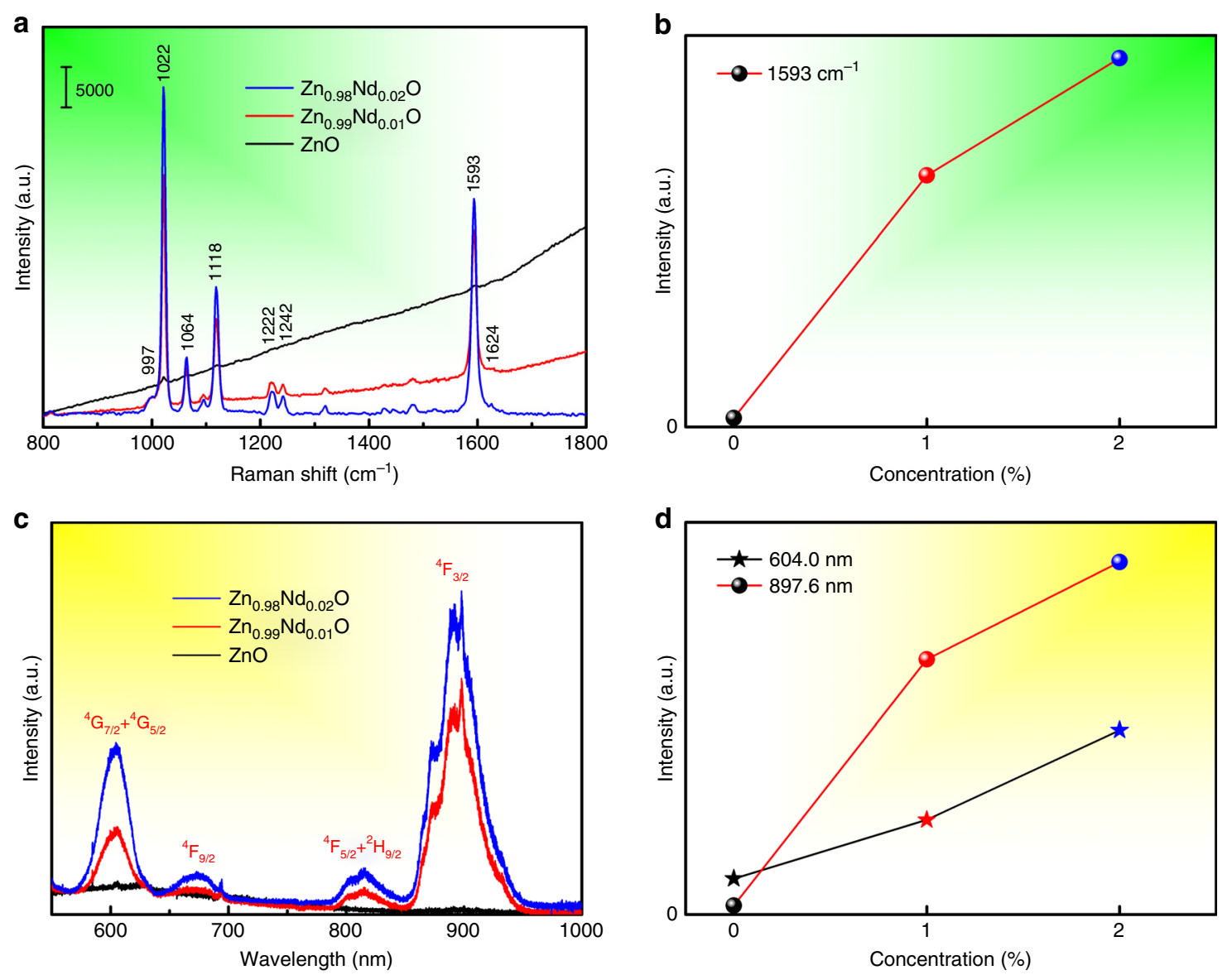

Fig. 2 To explore the relationship between SERS and PL, SERS spectra of 4-MPy adsorbed on $\mathrm{Zn}_{1-x} \mathrm{Nd}_{x} \mathrm{O}$ and PL spectra of $\mathrm{Zn}_{1-x} \mathrm{Nd}_{x} \mathrm{O}$ measured with laser lines of $\mathbf{5 1 4 . 5} \mathbf{~ n m}$. a SERS spectra of 4-MPy adsorbed on $\mathrm{Zn}_{1-x} \mathrm{Nd}_{x} \mathrm{O}(x=0.00,0.01,0.02)$ under a $514.5-\mathrm{nm}$ laser. $\mathbf{b}$ A plot of the SERS intensity of the $1593 \mathrm{~cm}^{-1}$ band of 4-MPy versus Nd concentration. $\mathbf{c}$ PL spectra of $\mathrm{Zn}_{1-x} \mathrm{Nd}_{x} \mathrm{O}(x=0.00,0.01,0.02)$ under a 514.5 -nm laser. d A plot of the PL intensity of 604.0 and $897.6 \mathrm{~nm}$ versus $\mathrm{Nd}$ concentration

spectral signal is enhanced after Nd doping, while the signal contributed by the fluorescence background is weakened. Figure $2 \mathrm{~b}$ shows the SERS intensity of the $1593 \mathrm{~cm}^{-1}$ band of 4-MPy plotted as a function of the Nd concentration. The SERS intensity increases with the $\mathrm{Nd}$ concentration and reaches a maximum for $\mathrm{Zn}_{0.98} \mathrm{Nd}_{0.02} \mathrm{O}$. Figure 2c displays the PL spectra of $\mathrm{Zn}_{1-{ }_{x}} \mathrm{Nd}_{x} \mathrm{O}$. The Nddoped $\mathrm{ZnO}$ exhibits dramatically sharp luminescence peaks, which is in sharp contrast with pure $\mathrm{ZnO}$. Moreover, luminescent peaks are located at 897.6, 815.1, 674.2, and $604.0 \mathrm{~nm}\left({ }^{4} \mathrm{~F}_{3 / 2},{ }^{4} \mathrm{~F}_{5 / 2}+{ }^{2} \mathrm{H}_{9 / 2},{ }^{4} \mathrm{~F}_{9 / 2}\right.$, and $\left.{ }^{4} \mathrm{G}_{7 / 2}+{ }^{2} \mathrm{G}_{5 / 2}\right)$, corresponding to the UV-vis absorption spectra ${ }^{20}$. Figure $2 \mathrm{~d}$ shows the Nd-ion doping concentration-dependent PL intensity of $\mathrm{Zn}_{1-x} \mathrm{Nd}_{x} \mathrm{O}$, which initially increases with the enhancement of the $\mathrm{Nd}$ concentration. Notably, the change in the PL intensity (Fig. 2d) is consistent with the change in the SERS intensity (Fig. 2b).

To further investigate the relationship between the PL and SERS of $\mathrm{Zn}_{1-x} \mathrm{Nd}_{x} \mathrm{O}$, we examined the change in the PL spectrum of $\mathrm{Zn}_{1-x} \mathrm{Nd}_{x} \mathrm{O}(x=0.00,0.01,0.02)$ with and without 4-MPy molecules. Figure 3 a shows that the $\mathrm{PL}$ signal of 4-MPy $+\mathrm{ZnO}$ is a simple superposition of the fluorescence of $\mathrm{ZnO}$ and 4-MPy, but the PL signal of $4-\mathrm{MPy}+\mathrm{Zn}_{0.98} \mathrm{Nd}_{0.02} \mathrm{O}$ is reduced in comparison with that of 4-MPy molecules. The intensities of the luminescence peaks at 897.6 and $815.1 \mathrm{~nm}\left({ }^{4} \mathrm{~F}_{3 / 2}\right.$ and $\left.{ }^{4} \mathrm{~F}_{5 / 2}+{ }^{2} \mathrm{H}_{9 / 2}\right)$ significantly decrease, while that of the luminescence peak at $604.0 \mathrm{~nm}\left({ }^{4} \mathrm{G}_{7 / 2}+{ }^{2} \mathrm{G}_{5 / 2}\right)$ shows a relatively small decrease. In addition, the SERS signal of 4-MPy+ $\mathrm{Zn}_{0.98} \mathrm{Nd}_{0.02} \mathrm{O}$ is significantly increased (Fig. 2a), indicating that there is obvious CT between $\mathrm{Zn}_{0.98} \mathrm{Nd}_{0.02} \mathrm{O}$ substrates and 4-MPy molecules.

To probe the CT mechanism between $\mathrm{Zn}_{1-{ }_{x}} \mathrm{Nd}_{x} \mathrm{O}$ $(x=0.00,0.01,0.02)$ and 4-MPy in the SERS spectrum, first, UPS and UV-vis spectra were used to determine the position of each energy level. The highest occupied molecular orbital (HOMO) and lowest unoccupied molecular orbital (LUMO) levels of 4-MPy are -9.77 and $-6.34 \mathrm{eV}$, respectively (calculated from Figs. S5 and S6). The maximum valence band (VB) and minimum 

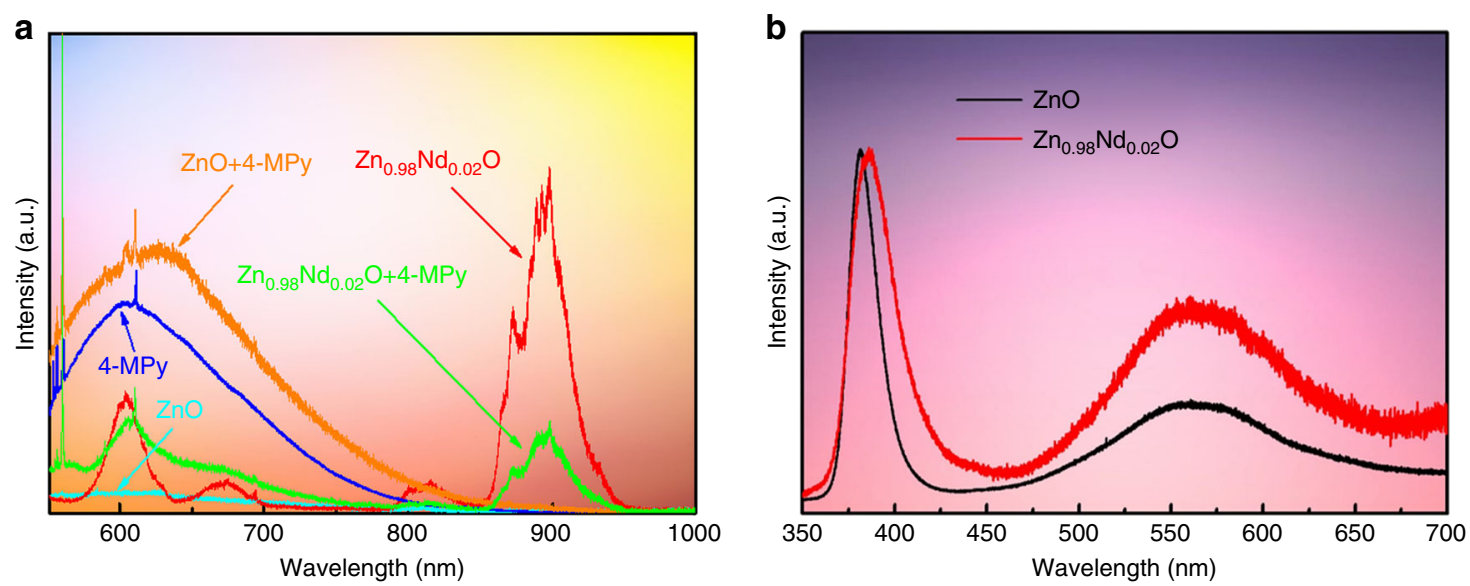

Fig. $3 \mathrm{PL}$ spectra of $\mathrm{Zn}_{1_{-x}} \mathrm{Nd}_{x} \mathrm{O}$ with and without 4-MPy molecules upon $\mathbf{5 1 4 . 5} \mathbf{n m}$ and $\mathbf{3 2 5} \mathbf{n m}$ laser excitation. a PL spectra of $Z \mathrm{nO}$, $\mathrm{Zn}_{0.98} \mathrm{Nd}_{0.02} \mathrm{O}$, 4-MPy, 4-MPy+ZnO, and 4-MPy+ $\mathrm{Zn}_{0.98} \mathrm{Nd}_{0.02} \mathrm{O}$ upon $514.5-\mathrm{nm}$ laser excitation; b PL spectra of $\mathrm{ZnO}, \mathrm{Zn}_{0.98} \mathrm{Nd}_{0.02} \mathrm{O}$, and $\mathrm{ZnO}$ upon 325-nm laser excitation

conduction band (CB) of $\mathrm{Zn}_{0.98} \mathrm{Nd}_{0.02} \mathrm{O}$ are -9.11 and $-6.00 \mathrm{eV}$ (calculation process in SI, Fig. S7), respectively. Figure $3 \mathrm{~b}$ shows the PL spectra of pure $\mathrm{ZnO}$ and $\mathrm{Zn}_{0.98} \mathrm{Nd}_{0.02} \mathrm{O}$ upon 325-nm laser excitation. The two samples consist of two emission bands: a near band edge at $\sim 383 \mathrm{~nm}$ and a wide deep level emission (DLE) from 480 to $660 \mathrm{~nm}^{21}$. The DLE is attributed to intrinsic defects, such as oxygen vacancies or various surface states $^{22}$. On the other hand, Nd doping increases the number of surface defects of $\mathrm{ZnO}$. These oxygen vacancies and surface defects induce new surface state energy levels (Ess) of $1.88-2.58 \mathrm{eV}^{13}$, located above the top of the VB (Fig. 3b). In addition, theoretical calculations indicate that the electronic ground state $\left({ }^{4} \mathrm{I}_{9 / 2}\right)$ of the $\mathrm{Nd}^{3+}$ ions is located $\sim 1 \mathrm{eV}$ below the top of the $\mathrm{VB}^{23}$. Thus, the excited-state energy levels of the $\mathrm{Nd}^{3+}$ ions are located at $-8.73,-8.61,-8.27$, and $-8.06 \mathrm{eV}$, respectively.

Based on the above results, we analyzed the enhancement mechanism of $\mathrm{Zn}_{1-x} \mathrm{Nd}_{x} \mathrm{O} \quad(x=0.00,0.01,0.02$, taking $\mathrm{Zn}_{0.98} \mathrm{Nd}_{0.02} \mathrm{O}$ as an example). As shown in Fig. $4 \mathrm{a}$, upon excitation at $514.5 \mathrm{~nm}(2.41 \mathrm{eV})$, the VB electrons of $\mathrm{ZnO}$ can be excited to Ess, transition to the LUMO level of the adsorbed 4-MPy molecules, and finally return to the $\mathrm{VB}$ of $\mathrm{ZnO}$ to release a Raman photon ${ }^{24}$. Considering that pure $\mathrm{ZnO}$ contains few oxygen defects, $\mathrm{ZnO}$ only undergoes $\mathrm{CT}$ in this process. Therefore, its SERS intensity is very low, and the PL signal with the probe molecules is superimposed.

As shown in Fig. 4 b, for $\mathrm{Zn}_{0.98} \mathrm{Nd}_{0.02} \mathrm{O}$, the $514.5-\mathrm{nm}$ laser is able to excite the electrons of the $4 f$ shell of the $\mathrm{Nd}^{3+}$ ions from the ground state $\left({ }^{4} \mathrm{I}_{9 / 2}\right)$ to the excited states $\left({ }^{4} \mathrm{~F}_{3 / 2},{ }^{4} \mathrm{~F}_{5 / 2}+{ }^{2} \mathrm{H}_{9 / 2},{ }^{4} \mathrm{~F}_{9 / 2}\right.$, and $\left.{ }^{4} \mathrm{G}_{7 / 2}+{ }^{2} \mathrm{G}_{5 / 2}\right)$. Then, the excited-state electrons transfer to the LUMO level and finally return to the ground state of the $\mathrm{Nd}^{3+}$ ions, releasing Raman photons. CT from the excited-state electrons of the $\mathrm{Nd}^{3+}$ ions to the 4-MPy molecule reduces the number of electrons returning to the ground state, resulting in fluorescence quenching of $\mathrm{Nd}^{3+}$ ions. The energy required for transition from the excited-state ${ }^{4} \mathrm{~F}_{3 / 2}$ to the LUMO is $2.39 \mathrm{eV}$, and the laser energy of $514.5 \mathrm{~nm}$ is exactly $2.41 \mathrm{eV}$. The two almost identical energy levels induce the occurrence of $\mathrm{CT}$ resonance. When ${ }^{4} \mathrm{~F}_{5 / 2}$ $+{ }^{2} \mathrm{H}_{9 / 2}$ transitions to a higher unoccupied molecular orbital, CT resonance can also occur. Thus, the luminescence peaks $\left({ }^{4} \mathrm{~F}_{3 / 2}\right.$ and $\left.{ }^{4} \mathrm{~F}_{5 / 2}+{ }^{2} \mathrm{H}_{9 / 2}\right)$ significantly decrease. However, the energy required to transfer electrons at ${ }^{4} G_{7 / 2}+{ }^{2} G_{5 / 2}$ to the 4-MPy molecule is much lower in comparison with that for ${ }^{4} \mathrm{~F}_{3 / 2}$. The CT resonance cannot occur, resulting in a lower probability of CT. As a consequence, the intensity of the ${ }^{4} G_{7 / 2}+{ }^{2} G_{5 / 2}$ luminescence peak has only a relatively small decrease. To better prove this electron transfer between $\mathrm{Zn}_{0.98} \mathrm{Nd}_{0.02} \mathrm{O}$ and 4-MPy, we measured the fluorescence lifetime of $\mathrm{Zn}_{0.98} \mathrm{Nd}_{0.02} \mathrm{O}$ before and after absorbing the 4-MPy molecule and collected their emission decays at ${ }^{4} G_{7 / 2}$ $+{ }^{2} \mathrm{G}_{5 / 2}$ (Fig. S8a) and ${ }^{4} \mathrm{~F}_{3 / 2}$ (Fig. S8b). It was found that when the 4-MPy molecule is adsorbed, the lifetime of the ${ }^{4} \mathrm{~F}_{3 / 2}$ energy level $(897.6 \mathrm{~nm})$ decreases rapidly, whereas the lifetime of the ${ }^{4} G_{5 / 2}+{ }^{2} G_{7 / 2}$ energy level $(604.0 \mathrm{~nm})$ remains almost unchanged. Therefore, the fluorescence quenching of $\mathrm{Nd}^{3+}$ ions significantly increases the SERS intensity of $\mathrm{Zn}_{1-{ }_{x}} \mathrm{Nd}_{x} \mathrm{O}$, realizing that the utilization of unique optical characteristics of $\mathrm{Nd}^{3+}$ ions promotes the SERS signal. As shown in the theoretical calculation (Fig. S9), the empty Nd $4 f$ impurity levels are close to the $\mathrm{Nd} 5 d$ levels, leading to mixing of the $4 f$ and small amounts of the $5 d$ orbitals, referred to as the $4 f-5 d$ orbital. Under laser irradiation, the $4 f$ ground-state electrons of $\mathrm{Nd}^{3+}$ ions can be excited into the higher empty $4 f-5 d$ levels, and then these excited $4 f-5 d$ electrons jump 


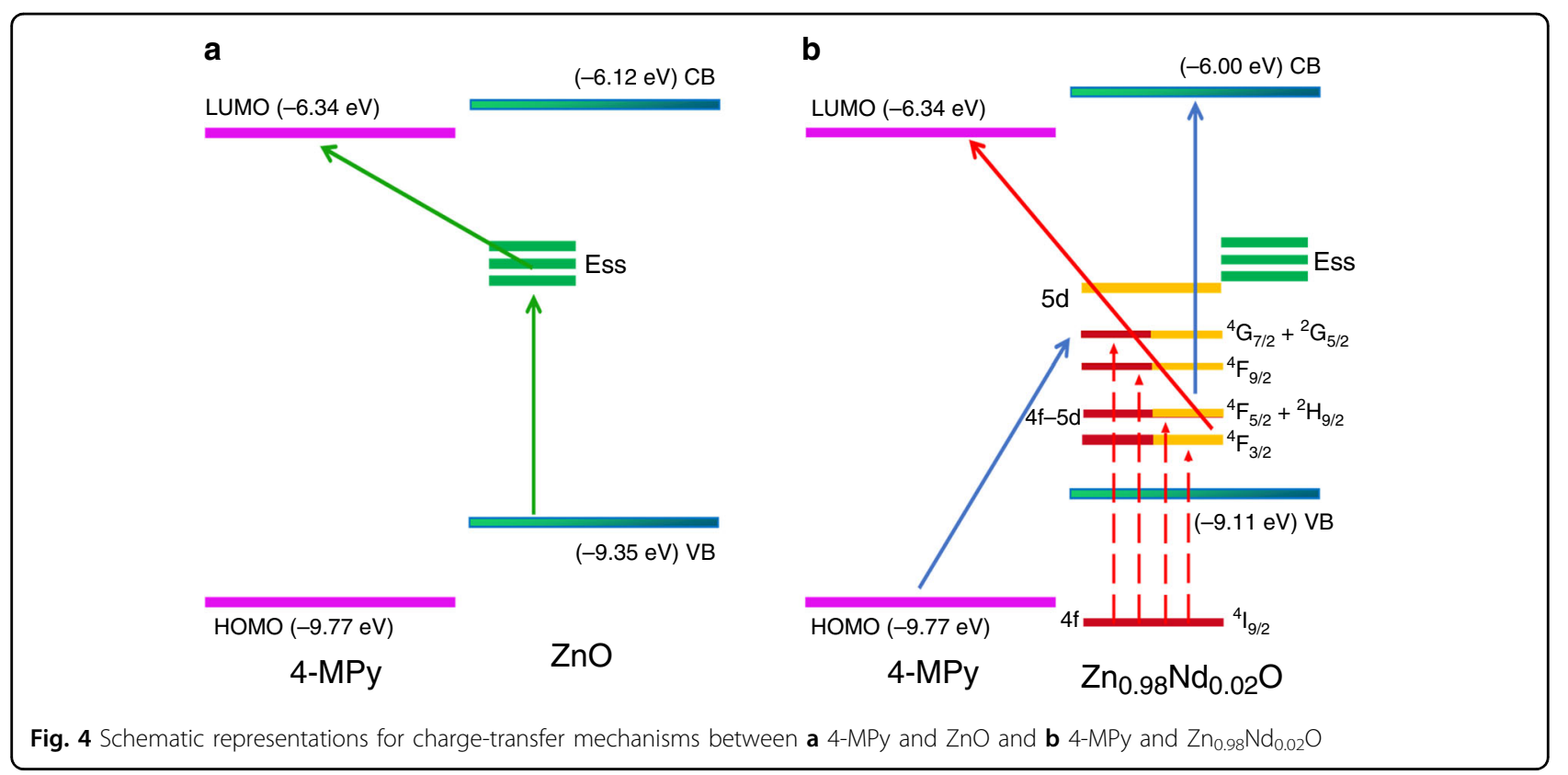

into the $5 \mathrm{~d}$ levels under continuous irradiation ${ }^{25}$. At the same time, the electrons in the $5 d$ orbital are reductive and easily lose electrons under irradiation by light ${ }^{26}$. Overall, the CT channel, originating from charge-transfer resonance, overcomes the effect of the $4 f$ levels shielded by external $5 s$ and $5 p$ electrons.

Furthermore, upon laser excitation, the HOMO-level electrons of the 4-MPy molecules transfer to the excited states and then to the $\mathrm{CB}$ of $\mathrm{Zn}_{1-x} \mathrm{Nd}_{x} \mathrm{O}$. They finally return to the HOMO level of the 4-MPy molecules, releasing Raman photons. This process inhibits the recombination of electrons and holes in the HOMO level, resulting in fluorescence quenching of 4-MPy molecules. The above CT processes work together toward the enhancement of SERS signals and significantly reduce the fluorescence background.

To further verify these CT processes, the SERS spectra of $\mathrm{Zn}_{1-x} \mathrm{Nd}_{x} \mathrm{O}(x=0.00,0.01,0.02)$ were analyzed under 633 and $785 \mathrm{~nm}$ laser irradiation (Fig. 4). The SERS spectra at $633 \mathrm{~nm}$ irradiation were essentially the same as the spectrum at $532 \mathrm{~nm}$ irradiation (Fig. 5a). However, the SERS spectra at $785 \mathrm{~nm}$ irradiation were significantly different (Fig. 5b): the SERS background increased significantly, while the SERS intensity was only slightly enhanced. The $633-\mathrm{nm}$ laser $(1.96 \mathrm{eV})$ can maximally excite electrons from ${ }^{4} \mathrm{I}_{9 / 2}$ to ${ }^{4} \mathrm{~F}_{9 / 2}(1.84 \mathrm{eV})$ and then transfer to the LUMO level $(1.93 \mathrm{eV})$. However, the 785$\mathrm{nm}$ laser $(1.58 \mathrm{eV})$ preferentially excites electrons from ${ }^{4} \mathrm{I}_{9 / 2}$ to ${ }^{4} \mathrm{~F}_{5 / 2}+{ }^{2} \mathrm{H}_{9 / 2}(1.52 \mathrm{eV})$, but the laser energy is not sufficient to again excite the electrons to the LUMO level $(2.27 \mathrm{eV})$. In the case of an increase in the PL of Nd-doped $\mathrm{ZnO}$, the inability of the substrate to reduce the PL signal via CT is responsible for the SERS background enhancement. Although the SERS spectra obtained under different excitation lines are different, they all support our proposed mechanism.

In summary, we analyzed the change between the PL and SERS relative intensities of $\mathrm{Nd}$-doped $\mathrm{ZnO}$ before and after the adsorption of probe molecules to explore the CT mechanisms in $\mathrm{Nd}$-doped $\mathrm{ZnO}$ systems. The results indicated that the unique CT between $\mathrm{Nd}^{3+}$ ions and probe molecules improves the SERS performance and naturally eliminates the SERS fluorescent background. Moreover, the mechanism is further confirmed by examining the SERS spectra under various excitation wavelengths. This work paves the way for developing novel molecular-sensing techniques.

\section{Methods}

$\mathrm{Zn}_{1-x} \mathrm{Nd}_{x} \mathrm{O}$ was synthesized using the coprecipitation method. In brief, $\mathrm{Zn}\left(\mathrm{NO}_{3}\right)_{2} \cdot 6 \mathrm{H}_{2} \mathrm{O}$ and $\mathrm{Nd}\left(\mathrm{NO}_{3}\right)_{3} \cdot 6 \mathrm{H}_{2} \mathrm{O}$ were dissolved in deionized water with a molar ratio where $\mathrm{Nd} /(\mathrm{Nd}+\mathrm{Zn})$ was $x: 1(x=0.00,0.005,0.01,0.015$, $0.0175,0.02,0.0225,0.03$ ). After stirring for $20 \mathrm{~min}$, $\mathrm{NH}_{4} \mathrm{HCO}_{3}$ aqueous solution was added. After stirring for $4 \mathrm{~h}$, the white precipitates were collected by centrifugation, washed with deionized water and ethanol several times, and then dried under vacuum at $80^{\circ} \mathrm{C}$ for $12 \mathrm{~h}$. Finally, the sample was further annealed in air for $1 \mathrm{~h}$ at $600{ }^{\circ} \mathrm{C}$ to obtain the final $\mathrm{Zn}_{1-x} \mathrm{Nd}_{x} \mathrm{O}(x=0.00,0.005$, $0.01,0.015,0.0175,0.02,0.0225$, and 0.03 ) products.

We evaluated the structural quality of the samples with X-ray diffraction (XRD, Rigaku D/Max 3C). X-ray photoelectron spectroscopy (XPS, VG ESCALAB 250X) was used to analyze the element content of the samples. The morphology was characterized by field emission SEM 

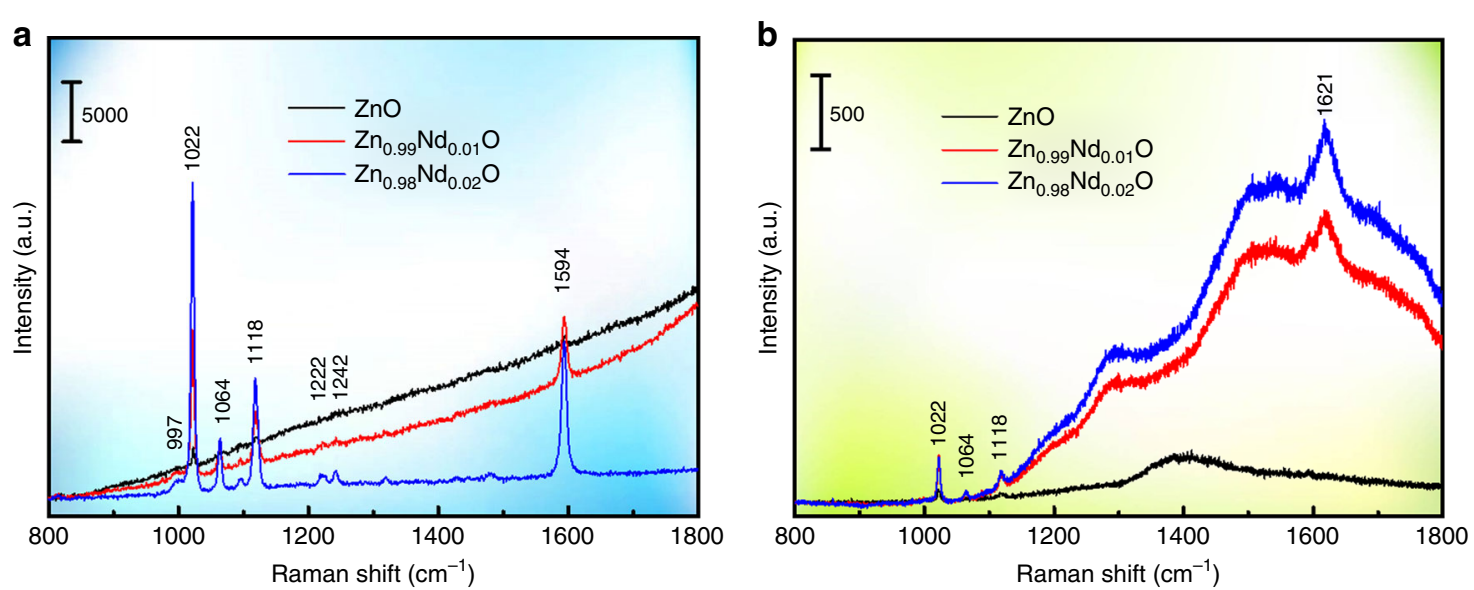

Fig. 5 SERS spectra of 4-MPy adsorbed on $\mathrm{Zn}_{1-x} \mathrm{Nd}_{x} \mathrm{O}(x=0.00,0.01,0.02)$ under different laser excitation: a $633 \mathrm{~nm}$ and $\mathbf{b} 785 \mathrm{~nm}$

(JEOL JSM-6700F) and TEM (JEM-2100HR). UV-vis absorption spectra were measured by a Shimadzu 3600 spectrometer. Under a $514.5 \mathrm{~nm}(2.41 \mathrm{eV}) \mathrm{Ar}^{+}$ion laser, the Renishaw inVia Raman system detected all SERS and PL signals with a laser power of $40 \mathrm{~mW}$, attenuation of $100 \%, 10$-s exposure time, and 1 scan.

\section{Acknowledgements}

This work was financially supported by the National Natural Science Foundation of China (Nos. 61675090, 21776110, 6170502021676115, 61705020, and 61575080); the National Youth Foundation of China (Nos. 61405072, $61704065,6170507821546013,61704065,61705078$, and 51609100); the Program for the Development of Science and Technology Jilin Province (Grant Nos. 20200201022JC, 20190103002JH, 20180520179JH20160101287JC, and 20180520179JH); the Thirteenth Five-Year Program for Science and Technology of Education Department of Jilin Province (Grant No. JJKH20190550KJ). The authors would like to thank the Prof. Lei Chen, Prof. Guochun Yang, and Prof. Yisong Zheng for the guidance.

\section{Author details}

${ }^{1}$ College of Science, Changchun University, Changchun 130022, China. ${ }^{2}$ National Demonstration Centre for Experimental Physics Education, Jilin Normal University, Siping 136000, China. ${ }^{3}$ Key Laboratory of Functional Materials Physics and Chemistry of the Ministry of Education, Jilin Normal University, Changchun 130012, China. ${ }^{4}$ Key Laboratory of Preparation and Application of Environmental Friendly Materials, Jilin Normal University, Ministry of Education, Changchun 130103, China. ${ }^{5}$ School of Materials Science and Engineering, Changchun University of Science and Technology, Changchun 130022, China

\section{Author contributions}

S.Y. and J. Yao contributed equally to this work. S.Y. conducted the experiments and revised the paper; J. Yao synthesized the samples and wrote the original draft preparation; Y.Q. tested the samples; M.H. and R.S. provided the theory calculation; M.G. designed the project and revised and edited the manuscript; D.H. and J. Yang participated in the discussion of the experimental data and provided good advice.

\section{Conflict of interest}

The authors declare that they have no conflicts of interest.

Supplementary information is available for this paper at https://doi.org/ 10.1038/s41377-020-00361-0.
Received: 13 January 2020 Revised: 6 June 2020 Accepted: 27 June 2020 Published online: 10 July 2020

\section{References}

1. Huang, Y. Z. et al. Nanowire-supported plasmonic waveguide for remote excitation of surface-enhanced Raman scattering. Light.: Sci. Appl. 3, e199 (2014).

2. Yao, J. C. et al. AgNPs decorated Mg-doped ZnO heterostructure with dramatic SERS activity for trace detection of food contaminants. J. Mater. Chem. C. 7. 8199-8208 (2019).

3. Shan, X. Y. et al. Mesoporous $\mathrm{TiO}_{2}$ nanofiber as highly efficient sulfur host for advanced lithium-sulfur batteries. Chin. J. Mech. Eng. 32, e60 (2019).

4. Yao, J. C. et al. Improved charge transfer and hot spots by doping and modulating the semiconductor structure: a high sensitivity and renewability surface-enhanced Raman spectroscopy substrate. Langmuir 35, 8921-8926 (2019).

5. Quan, Y. N. et al. ZnO nanoparticles on $\mathrm{MoS}_{2}$ microflowers for ultrasensitive SERS detection of bisphenol A. Microchim. Acta 186, 593 (2019).

6. Hugall, J. T. \& Baumberg, J. J. Demonstrating photoluminescence from Au is electronic inelastic light scattering of a plasmonic metal: the origin of SERS backgrounds. Nano Lett. 15, 2600-2604 (2015).

7. Weber, M. L. et al. Super-resolution imaging reveals a difference between SERS and luminescence centroids. ACS Nano 6, 1839-1848 (2012).

8. Lin, K. Q. et al. Plasmonic photoluminescence for recovering native chemical information from surface-enhanced Raman scattering. Nat. Commun. 8, 14891 (2017).

9. Williams, F. E. \& Eyring, H. The mechanism of the luminescence of solids. J. Chem. Phys. 15, 289-304 (1947).

10. Gao, M. et al. Strong red emission and catalytic properties of $\mathrm{ZnO}$ by adding $\mathrm{Eu}_{2} \mathrm{O}_{3}$ shell. J. Alloy. Compd. 724, 537-542 (2017).

11. Zheng, J. T. et al. Electrical and SERS detection of disulfide-mediated dimerization in single-molecule benzene-1,4-dithiol junctions. Chem. Sci. 9, 5033-5038 (2018).

12. Kiguchi, M. et al. Surface enhanced Raman scattering on molecule junction. Appl. Mater. Today 14, 76-83 (2019).

13. Xue, X. X. et al. Surface-enhanced Raman scattering of molecules adsorbed on Co-doped ZnO nanoparticles. J. Raman Spectrosc. 43, 61-64 (2012).

14. Yang, S. et al. Controllable morphology and tunable colors of $\mathrm{Mg}$ and Eu ion co-doped $\mathrm{ZnO}$ by thermal annealing. CrystEngComm 16, 6896-6900 (2014).

15. Wang, X. T. et al. Remarkable SERS activity observed from amorphous ZnO nanocages. Angew. Chem. Int. Ed. 56, 9851-9855 (2017).

16. Gao, M. et al. Zinc oxide nanotubes decorated with silver nanoparticles as an ultrasensitive substrate for surface-enhanced Raman scattering. Microchim. Acta 179, 315-321 (2012). 
17. Wang, S. G. et al. Thermally removable in-situ formed $\mathrm{ZnO}$ template for synthesis of hierarchically porous $\mathrm{N}$-doped carbon nanofibers for enhanced electrocatalysis. Nano Res. 9, 2270-2283 (2016).

18. Alam, U. et al. Comparative photocatalytic activity of sol-gel derived rare earth metal (La, Nd, Sm and Dy)-doped ZnO photocatalysts for degradation of dyes. RSC Adv. 8, 17582-17594 (2018).

19. Cheng, X. B. et al. Waterproof coatings for high-power laser cavities. Light. Sci. Appl. 8, 12 (2019).

20. Gao, M. et al. Novel composite nanomaterials with superior thermal and pressure stability for potential LED applications. J. Alloy. Compd. 734, 282-289 (2018).

21. Wang, X. H. et al. The photoluminescence properties of $\mathrm{ZnO}$ whiskers. J. Cryst. Growth 263, 316-319 (2004).
22. Vanheusden, $\mathrm{K}$. et al. Mechanisms behind green photoluminescence in $\mathrm{ZnO}$ phosphor powders. J. Appl. Phys. 79, 7983-7990 (1996)

23. Balestrieri, $\mathrm{M}$. et al. Efficient energy transfer from $\mathrm{ZnO}$ to $\mathrm{Nd}^{3+}$ ions in $\mathrm{Nd}$ doped $\mathrm{ZnO}$ films deposited by magnetron reactive sputtering. J. Mater. Chem. C. 2, 9182-9188 (2014).

24. Yilmaz, M. et al. Micro-/nanostructured highly crystalline organic semiconductor films for surface-enhanced Raman spectroscopy applications. Adv. Funct. Mater. 25, 5669-5676 (2015).

25. Meng, J. L. et al. Luminescence mechanistic study of $\mathrm{BaLaGa}_{3} \mathrm{O}_{7}: \mathrm{Nd}$ using density functional theory calculations. Inorg. Chem. 55, 2855-2863 (2016).

26. Qiao, Y. S. \& Schelter, E. J. Lanthanide photocatalysis. Acc. Chem. Res. 51, 2926-2936 (2018) 